\title{
Breathlessness and portable oxygen in chronic obstructive airways disease
}

\author{
JC WATERHOUSE, P HOWARD \\ From the University Department of Medicine, Royal Hallamshire Hospital, Sheffield
}

\begin{abstract}
Breathlessness was measured in 20 patients with severe chronic obstructive lung disease by the use of a visual-analogue scale. Severe resting arterial hypoxaemia was not a feature. $\stackrel{\oplus}{\perp}$ The severity of breathlessness measured in this way did not correlate well with the results of $\dot{\omega}_{0}$ spirometric tests or with walking ability. The use of portable oxygen was studied during simple ${ }^{N}$ walking tests for its effect on walking ability and the sensation of breathlessness. Portable oxygen improved exercise capacity but a placebo effect of the system probably accounted for some of the improvement. A clear improvement of distressing breathlessness was observed and represented a을 useful therapeutic response. Breathlessness and simple exercise ability were shown to respond independently to oxygen breathing. The value of short-term intermittent oxygen in patients with severe chronic obstructive lung disease needs to be evaluated in terms of both exercise ability and breathlessness.
\end{abstract}

The most frequent complaint of patients with chronic obstructive lung disease is breathlessness. Other symptoms of the disease are largely ignored until breathlessness begins to limit exercise capacity. Breathlessness as assessed by grades used by the Medical Research Council questionnaire on respiratory symptoms ${ }^{1}$ increases as the spirometric measurements of airways obstruction decrease but the relationship is subject to large variability. For example, a common clinical observation is that one patient with a forced expiratory volume $\left(\mathrm{FEV}_{1}\right)$ of 1 litre will profess such severe disability as to be housebound and yet another with identical functional values will be able to walk to work, albeit at a limited pace, and manage a light job.

The measurement of sensations as complex as breathlessness is particularly difficult. Indirect measurements, respiratory function tests, exercise tests, and questionnaires based on exercise performance are usually employed. Objective assessment is invariably coloured by personality traits which exaggerate or diminish the real sensory disturbance. This was recognised in 1969 by Burns and Howell, ${ }^{2}$ who found disproportionately severe breathlessness in chronic bronchitis related to depression, anxiety,

Address for reprint requests: Dr $P$ Howard, Department of Medicine, Royal Hallamshire Hospital, Sheffield S10 2JF.

Accepted 21 December 1982

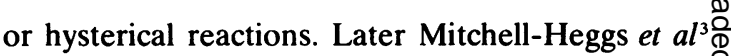
obtained improvement of breathlessness by using diazepam in emphysematous patients with severe응 dyspnoea. The fact that most patients with chronic obstructive lung disease do not have a psychiatric disorder but have the normal span of individual per-sonalities, and range from those who underestimate $\vec{\sigma}$ their symptoms to those who perpetually amplify or exaggerate them, is sufficient to affect profoundly the individual interpretation of disability from a3 symptom such as breathlessness. Visual-analoguen scales have been found useful in measuring sensa- -3 tions. ${ }^{34}$ In this study a visual-analogue scale of $100^{\circ}$ $\mathrm{mm}$ length was used to allow the patient with chronic obstructive lung disease to express feelingso about symptoms. This simple technique was used to quantify breathlessness repeatedly at rest, duringo exercise with the patient breathing air, and during exercise with portable oxygen. We wished to deter-N mine whether a highly emotive treatment, oxygen breathing, might affect the sensation of breathlessness independently of its effect on exercise capacity. $\frac{\mathscr{Q}}{\mathbb{D}}$

\section{Methods}

Twenty patients, 11 men and nine women, with typical but severe obstructive lung disease were्ष्क studied. They attended a bronchitis clinic and the principal complaint was breathlessness. No patienk had obvious psychiatric disorder but no formab 
psychiatric assessment was carried out. The patients attended the respiratory function laboratory in a stable period, when there had been no recent infection or change in exercise capacity for daily walking.

A questionnaire on breathlessness similar to that of Fletcher ${ }^{1}$ was completed. Patients were asked to grade their breathlessness by placing a cross on a $100 \mathrm{~mm}$ line. The line was printed in the centre of a sheet of paper with the words "None" at the lefthand side and "Severe" at the right-hand side. An instruction requesting a cross to be placed between the limits according to how severe they considered their breathlessness to be was also printed on the sheet. Thus all patients did precisely the same test. No attempt was made to fix a limit to the scale by means of exhausting exercises to provide an example of severe breathlessness. Spirometry (FEV 1 and FVC) was performed, lung volumes were measured by the helium-dilution technique, and where possible single-breath transfer factor was measured. Five-minute walking tests ${ }^{5}$ were performed in the hospital corridors with the patient breathing air and oxygen in random order. No practice walks were done. During separate walks the patient breathed ambient air, oxygen at 2 and 4 litres per minute through nasal catheters from a Portagen portable oxygen apparatus, and air at 3 $1 /$ min through the same apparatus. The patient was informed that he was breathing $3 \mathrm{l} / \mathrm{min}$ of oxygen during the latter air-breathing spell. The ambient air breathing test was included in the randomisation procedure. The apparatus weighed around $2 \mathrm{~kg}$ (between 4 and $5 \mathrm{lb}$ ) loaded for these tests, the Portagen system being used, and it was carried by the patient. At least half an hour's rest was allowed between walks. All walks were conducted by one of us (JW) walking behind the patient, who was allowed to set his own pace and stops. The distance walked was recorded. No interference of any sort was allowed during the walk but in 10 patients the pulse rate and respiratory rate were recorded within one minute of completion. A visual-analogue scale of effort required was completed within one minute of the walk. The patient was asked how difficult he had found it. The same procedure was followed as for the visual-analogue scale for breathlessness except that the instructions now contained the word "effort." The limit words on the $100 \mathrm{~mm}$ line were the same. It was realised that although breathlessness would be a major component of the effort this would also include symptoms such as general fatigue and muscle aching as these are the symptoms that terminate formal exercise tests such as bicycle ergometry in such patients.

After an interval of three weeks to three months patients were asked to repeat the tests. The order of performing the four walks was changed on the second occasion but the tests were otherwise identical. Student's $t$ test for paired data was used to make statistical analysis. All patients gave informed consent to the tests.

\section{Results}

The 20 patients studied had a mean age of $61.2 \pm 11.9$ years. Table 1 shows details of their respiratory function. All had severe breathlessness at rest and advanced airways obstruction.

The figure relates the measurements of breathlessness calculated in millimetres from the zero point on the visual-analogue scale $\left(\mathrm{VA}_{B}\right)$ to the $\mathrm{FEV}_{1}$ made at the initial assessment. Despite a mean value of only 0.92 litres for $F E V_{1}$ values of $V_{B}$ cover the full length of the scale (for $V_{A}$ against $\left.\mathrm{FEV}_{1} \mathrm{r}=0 \cdot 103\right)$. This accords with the clinical observation that some patients with advanced airways obstruction do not appear to be unduly disturbed by breathlessness yet others seem severely

Table 1 Respiratory function in the 11 men and nine women during the walking tests

\begin{tabular}{|c|c|}
\hline & Mean $\pm S D$ \\
\hline $\begin{array}{l}\text { Age (y) } \\
\mathrm{FEV}_{1}(1) \\
\mathrm{FVC}(\mathrm{l}) \\
\mathrm{PaO}_{2}(\mathrm{kPa}) \\
\mathrm{PaCO}_{2}(\mathrm{kPa}) \\
\mathrm{VAB}_{\mathrm{B}}(\mathrm{mm}) \\
\mathrm{RV} / \mathrm{TLC}(\%) \\
\text { TLco (\% predicted) }\end{array}$ & $\begin{array}{c}61.2 \pm 11.9 \\
0.92 \pm 0.62 \\
1.91 \pm 1.08 \\
8.9 \pm 2.1 \\
5.2 \pm 1.0 \\
52.7 \pm 20 \\
56.1 \pm 10.3^{*} \\
49.8 \pm 21.2 \dagger\end{array}$ \\
\hline
\end{tabular}

*Derived from 15 patients.

t.Derived from 10 patients.

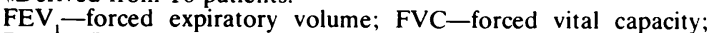
$\mathrm{PaCO}_{2}, \mathrm{PaO}_{2}$-arterial carbon dioxide and oxygen tensions; $\mathrm{VA}_{\mathrm{B}}$ - visual analogue distance in $\mathrm{mm}$ representing breathlessness; $\mathrm{RV} / \mathrm{TLC}$-residual volume as percentage of total lung capacity; TLco-transfer factor for carbon monoxide. ${ }^{24}$

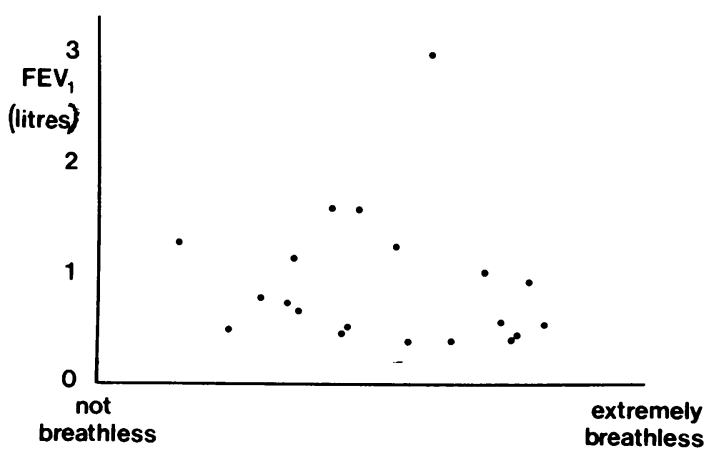

Forced expiratory volume $\left(F E V_{1}\right)$ and breathlessness measured by the visual analogue scale $\left(V A_{B}\right)$, on which the ratings range from severe down to mild despite low levels of FEV . 
Table 2 Distance walked by the 20 patients while they were breathing various gas mixtures

\begin{tabular}{|c|c|}
\hline & Mean $( \pm S D)$ distance walked $(m)$ \\
\hline Air & $152 \cdot 6 \pm 67 \cdot 5$ \\
\hline $\begin{array}{l}\text { Oxygen } \\
2 \mathrm{l} / \mathrm{min} \\
4 \mathrm{l} / \mathrm{min}\end{array}$ & $\begin{array}{l}172 \cdot 6 \pm 62 \cdot 1 \\
174 \cdot 0 \pm 64 \cdot 8\end{array}$ \\
\hline $\begin{array}{l}\text { Air thought to be } \\
\text { oxygen }(3 \mathrm{l} / \mathrm{min})\end{array}$ & $165 \cdot 6 \pm 51 \cdot 0$ \\
\hline
\end{tabular}

Table 3 Effort as represented on the visual-analogue scale $\left(V A_{E}\right)$ by the 20 patients after breathing different gas mixtures during the five-minute walks

\begin{tabular}{ll}
\hline & Mean $( \pm S D) V A_{E}(\mathrm{~mm})$ \\
\hline Air & $62.4 \pm 24 \cdot 1$ \\
Oxygen & \\
$\quad 2 \mathrm{~V} / \mathrm{min}$ & $41.4 \pm 27.4$ \\
$\quad \begin{array}{l}\mathrm{l} / \mathrm{min} \\
\text { Air thought to be } \\
\text { oxygen (3 } \mathrm{lmin})\end{array}$ & $54.7 \pm 30.7$ \\
\hline
\end{tabular}

disabled. The relationship with FVC $(r=0.06)$ was also not significant. $V A_{B}$ at the initial assessment did not seem to determine walking capability as there was no relationship with distance achieved during the breathing of air without the apparatus ( $\mathrm{r}=$ $0 \cdot 15)$. Table 2 shows walking distances during the four procedures. Standard deviations are large because of the wide variation in walking ability at this level of airway function. The distance the patients walked in five minutes was significantly greater during the breathing of 2 and $4 \mathrm{l} / \mathrm{min}$ of oxygen. While they were breathing air believing it to be 3 $1 /$ min of oxygen they walked a greater distance than while breathing ambient air (152.6 \pm 67.5 metres) but the difference was not significant. They walked further while breathing oxygen at $4 \mathrm{l} / \mathrm{min}$ (174.0 \pm 64.8 metres) than while breathing air believing it to be oxygen $(165.6 \pm 51.0 \mathrm{~m}$; $\mathrm{p}<0.03$ ).

Visual-analogue scaling measuring the effort of walking $\left(\mathrm{VA}_{\mathrm{E}}\right)$ during the four procedures correlated well with $\mathrm{VA}_{B}$, suggesting that effort as we measure it is largely determined by breathlessness ( $r$ $=0 \cdot 66)$. $\mathrm{VA}_{\mathrm{E}}$ was very much lower during both walks performed while the patients were breathing oxygen than when they were breathing ambient air (p < 0.005: table 3). It was lower, though not $\vec{\Rightarrow}$ significantly so, when they were breathing air from $\stackrel{?}{\rightarrow}$ the apparatus believing it to be oxygen than during ambient air breathing; but, more importantly, it was significantly less during oxygen breathing ( 2 or $4 \frac{\omega}{\partial}$ $1 / \mathrm{min})$ than during air breathing from the apparatus $\stackrel{\mathbb{\Omega}}{\Omega}$ $(p<0.05)$. Thus there appears to be a real advantage of oxygen breathing in reducing the sensation $\vec{O}$ of breathlessness, which can clearly be identified as something different from impaired exercise capac- $\bar{\omega}$ ity.

Table 4 shows the changes in pulse rate and $\overrightarrow{\vec{x}}$ respiratory rate after exercise. While increases in $\omega_{\infty}$ pulse rate were comparable during the air and the $A$ oxygen phases the rise of respiratory rate in the walk $\omega$ during the breathing of oxygen $(4 \mathrm{l} / \mathrm{min})$ was much $N$

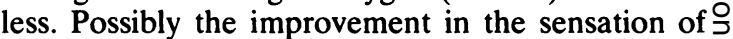
breathlessness is related to the reduced respiratory drive during oxygen breathing.

Finally, we tested the reproducibility of the measurements, comparing the preliminary assessments of $\overrightarrow{0}$ breathlessness and the assessments of effort during $\omega$ the four walking tests on the two occasions. The correlation coefficients were respectively 0.89 and $0 \cdot 79$.

\section{Discussion}

In the use of the visual-analogue scale no attempt흘 was made to fix the limits of the $100 \mathrm{~mm}$ line and in the preliminary assessment no attempt was made to illustrate severe breathlessness. The patient set his own limits on what he regarded as no breathlessness and severe breathlessness. During the four walking tests the technician walked behind the patient and ${ }^{x}$ no measurements were made until the test was com-3. pleted. In this way the patient made his decision without intrusion. Breathlessness recorded during preliminary assessment presumably reflects the patient's immediate feelings coloured by his or her? experiences of the recent past. Repeat measure-o ments after an interval of up to three months were remarkably close, suggesting that the individualo expressions of the patient's sensations were veryn reproducible. Inter-patient differences were largen despite low levels of airway function. No relation- $-\sigma$ ship was observed between the initial visualanalogue grading of breathlessness and the results of

Table 4 Changes in pulse and respiratory rates in 10 of the patients during five-minute walks while they were breathing air? and oxygen respectively

\begin{tabular}{|c|c|c|c|c|}
\hline & \multicolumn{2}{|l|}{ Air } & \multicolumn{2}{|c|}{ Oxygen (4 l/min) } \\
\hline & Start & Finish & Start & Finish \\
\hline $\begin{array}{l}\text { Mean }( \pm S D) \text { pulse rate per min } \\
\text { Mean }( \pm S D) \text { respiratory rate per min }\end{array}$ & $\begin{array}{l}82.6 \pm 12.5 \\
23.6 \pm 6.89\end{array}$ & $\begin{array}{r}92 \cdot 2 \pm 13 \cdot 8 \\
28 \cdot 0 \pm 9 \cdot 5\end{array}$ & $\begin{array}{l}82 \cdot 1 \pm 11 \cdot 4 \\
22 \cdot 0 \pm 7 \cdot 2\end{array}$ & $\begin{array}{l}89 \cdot 3 \pm 16 \cdot 2 \\
23 \cdot 6 \pm 10 \cdot 0\end{array}$ \\
\hline
\end{tabular}


simple spirometric tests, Fletcher-grade breathlessness, and/or distance walked during the five minute walking test. ${ }^{5}$ Most chest physicians observe patients with low $\mathrm{FEV}_{1}$ who do not complain of severe breathlessness. This impression is confirmed and suggests that bronchitis clinics might selectively attract patients who feel they have dyspnoea. The poor relationship between the effort of walking and distance achieved reflects the same property. The factors which control distance or maximum exercise capacity under defined circumstances differ from sensations evolved during their performance. It is important to appreciate this difference as it may be possible to improve the nature of evolved sensation without changing exercise performance.

Most of our patients did not have severe blood gas disturbance. It has always been debatable as to whether such patients with obstructive lung disease benefit from portable oxygen during walking. Portable oxygen was first considered of value in 1956 by Cotes and Gilson. ${ }^{6}$ Breathing $4 \mathrm{l} / \mathrm{min}$ doubled walking distance on a treadmill; no control subjects were investigated. Pierce $e t a l^{7}$ found that both training and exercise programmes were less stressful in physiological terms when supplementary oxygen was used. The first attempt at a controlled study was made by Bradley et al. ${ }^{8}$ Patients with chronic airways obstruction exercised while breathing air, oxygen, and compressed air. No improvement of exercise capacity was observed between air, oxygen and compressed air breathing. Portable liquid air and oxygen breathing was compared in nine patients in a crossover study during walking by Lilker et al..$^{9}$ All patients said that they felt better using the portable apparatus but only three had improved exercise capacity during oxygen breathing. The first attempt to measure breathlessness independently of exercise performance in bronchitis was made by Woodcock et al.$^{10}$ Breathlessness was measured with a visualanalogue scale and exercise capacity assessed during a six-minute hospital corridor walk and by progressive exercise on a treadmill. Compressed air and oxygen were administered in double-blind fashion. Oxygen reduced breathlessness scores during exercise and slightly increased the distance walked in the hospital corridor and on the treadmill.

In our study the improvement in breathlessness during oxygen walking was substantial. The placebo test, although producing an improvement that was not quite statistically significant, gave a mean value equal to half the improvement. If more patients were studied probably placebo effects would be shown to account for at least half of the observed response. The difference in results between flow rates of 2 and $4 \mathrm{l} / \mathrm{min}$ was trivial. Improvement was associated with a relative fall of respiratory rate.
Resting respiratory rates were higher than in normal people but would be considered reasonable for this type of disabled patient. During oxygen breathing the respiratory rate hardly changed during exercise, in contrast to the further increase seen during air breathing. As exercise times were short the observed changes of respiratory rate might have been due to reflex effects.

The inappropriate awareness of breathing that constitutes breathlessness has been studied in terms of altered control of respiration, ${ }^{11-14}$ disturbed recognition of the detection of added resistive and elastic loads, ${ }^{15-17}$ inappropriate pulmonary afferent receptor firing, ${ }^{18-20}$ and disturbed proprioception from the chest wall and abdomen. ${ }^{21-23}$ The sensation of breathlessness which allows one patient with bronchitis to be only trivially disturbed by his feelings and another with identical functional disturbance to profess severe disability is probably due to a central assimilation of such physiological information with the psychological factors that make up personality.

The visual-analogue scale measures this combined effect and should be capable of testing benefit when breathlessness is subjected to independent therapeutic intervention. Burns and Howell, ${ }^{2}$ in their study of disproportionately severe breathlessness in chronic bronchitis with depression, anxiety and hysterical reactions, found that treatment of the psychiatric disturbance improved breathlessness. Later Mitchell-Heggs et $a^{3}$ using diazepam improved breathlessness in four patients described as "pink puffers," but the soporific effect has precluded more general use. Morphine and its derivatives have long been known to alleviate breathlessness in pulmonary oedema and bronchial asthma but its central respiratory depressant effect has made it unsuitable for use in bronchial asthma and chronic airways obstruction.

In summary, breathlessness can be measured as a sensation independent of airway function and exercise capacity by the use of the visual-analogue scale in chronic obstructive lung disease. Severe breathlessness may be treatable without necessarily improving airway function or exercise capacity in patients with heightened sensory awareness of breathlessness. Portable oxygen increases the distance walked and reduces breathlessness. The latter effect would seem to be the more important but much further work is needed to discover mechanisms and to select the patients most likely to benefit.

\section{References}

${ }^{1}$ Medical Research Council. Short questionnaire on respiratory symptoms. $\mathrm{Br}$ Med J 1960;ii: 1665. 
${ }^{2}$ Burns BH, Howell JBL. Disproportionately severe breathlessness in chronic bronchitis. $Q \mathrm{~J}$ Med 1969;38:277-94.

${ }^{3}$ Mitchell-Heggs P, Murphy K, Minty K, et al. Diazepam in the treatment of dyspnoea in the "pink puffer" syndrome. $Q J$ Med 1980;49:9-20.

${ }^{4}$ Bond $\mathrm{A}$, Lader $\mathrm{M}$. The use of analogue scales in rating subjective feelings. B J Med Psychol 1974;47:211-8.

${ }^{5}$ McGavin CR, Gupta SP, McHardy GJR. Twelve minute walking test for assessing disability in chronic bronchitis. Br Med J 1976;i:822-3.

${ }^{\circ}$ Cotes JE, Gilson JC. Effect of oxygen on exercise ability in chronic respiratory insufficiency. Lancet 1956; 872-6.

${ }^{7}$ Pierce AK, Paez PN, Miller WF. Exercise training with the aid of portable oxygen supply in patients with emphysema. Am Rev Respir Dis 1965;91:653-9.

${ }^{8}$ Bradley BL, Garner AE, Biliu D. Oxygen assisted exercise in chronic obstructive lung disease. Am Rev Respir Dis 1978;118:239-43.

${ }^{9}$ Lilker EJ, Karnick A, Lerner L. Portable oxygen in chronic obstructive lung disease with hypoxaemia and cor pulmonale. Chest 1975;68:236-41.

${ }^{10}$ Woodcock AA, Gross ER, Geddes DM. Oxygen relieves breathlessness in "pink puffers." Lancet 1981;i:907-9.

${ }^{11}$ Lane DJ, Howell JBL. Relationship between sensitivity to $\mathrm{CO}_{2}$ and clinical features in patients with chronic airways obstruction. Thorax 1970;25:150-9.

${ }^{12}$ Cherniack RM, Sindal DP. The effect of obstruction to breathing on ventilatory response to $\mathrm{CO}_{2} . \mathrm{J}$ Clin Invest 1956;35:1286-90.

${ }^{13}$ Kepron W, Cherniack RM. The ventilatory response to hypercapnia and hypoxaemia in chronic obstructive lung disease. Am Rev Respir Dis 1973;108:843-9.
${ }^{14}$ Matthews AW. The relationship between central $\mathrm{CO}_{2} \Rightarrow$ sensitivity and clinical features in patients with chronic $\stackrel{\vec{\rho}}{\rightarrow}$ airways obstruction. $Q J$ Med 1977;46:179-95.

${ }^{15}$ Campbell EJM, Freedman S, Smith PS, Taylor ME. Ability of man to detect added elastic loads to breathing. Clin Sci 1960;20:228-31.

${ }^{16}$ Campbell EJM, Bennett ED, Reubenstein D. The ability $\stackrel{\mathbb{D}}{2}$ to distinguish between added elastic and resistive loads to breathing. Clin Sci 1963;24:201-7.

17 West DWM, Ellis CG, Campbell EJM. Ability of man to $\vec{\circ}$ detect increases in his breathing. J Appl Physiol $\overrightarrow{+}$ 1979;39:272-6.

${ }^{18}$ Guz A, Noble MIM, Widdicombe JG, Trenchard D. The role of vagal and glossopharyngeal afferent nerves in $\times$ respiratory sensation, control of breathing and arterial $\omega_{\text {w }}$ pressure regulation in conscious man. Clin Sci 1966;30:161-70.

19 Paintal AS. Vagal sensory receptors and other reflex $\stackrel{\omega}{\circ}$ effects. Physiol Rev 1973;53:159-227.

${ }^{20} \mathrm{Guz}$ A. Respiratory sensations in man. Br Med Bull 윽 1977;33:175-7.

${ }^{21}$ Newson-Davis J. Contribution of somatic receptors in the chest wall to respiratory sensation. In: Howell JB, Campbell EJM, eds. Breathlessness: proceedings of an $\rightarrow$ international symposium. Oxford: Blackwell Scientific $\stackrel{\varrho}{\infty}$ Publications, 1966.

${ }^{22}$ Altose MD, Shaban IA. Intercostal muscle activity in $\square$ chronic obstructive pulmonary disease. Chest 1980;77, suppl: 299-300.

${ }^{23}$ Todisco T. Thoraco-abdominal mechanics in dyspnoea. Respiration 1981;42:77-83.

${ }^{24}$ Cotes JE. Lung function: assessment and application in $\stackrel{2}{\mathbb{Q}}$ medicine. 4th ed. Oxford: Blackwell Scientific Publications, 1979. 